\title{
PENGEMBANGAN SISTEM INFORMASI PELAYANAN PUBLIK PERIZINAN PEREDARAN HASIL HUTAN
}

\author{
Marleni Anike ${ }^{1}$, Imen Fattu ${ }^{2}$ \\ ${ }^{1,2}$ Jurusan Teknik Informatika Fakultas Teknik Informatika STIKOM Artha Buana Kupang \\ Jln. Samratulangi 3 No 1, Oesapa Barat, Kelapa Lima, Walikota, Nusa Tenggara Timur \\ 1rypy03lny@gmail.com \\ ${ }^{2}$ if1998@gmail.com
}

\begin{abstract}
Abstrak - Aplikasi p4H2 merupakan model aplikasi website yang khusus dikembangkan untuk KPH Wilayah Kota Kupang. Dimana cikal bakal dikembangkannya aplikasi ini adalah KPH Wilayah Kota Kupang merupakan salah satu instansi pemerintah yang bertanggung jawab untuk melaksanakan pelayanan publik perizinan peredaran hasil hutan di Kota Kupang dalam rangka upaya pemenuhan kebutuhan masyarakat maupun dalam rangka pelaksanaan peraturan perundang-undangan. Guna memaksimalkan efektifitas kerja, proses perizinan peredaran hasil hutan maka dikembangkanlah aplikasi ini untuk memangkas waktu, tenaga serta biaya baik petugas maupun pemohon. Untuk mengembangkan aplikasi digunakan PHP, XAMPP, Bootstrap 4. Perancangan sistemnya secara terstruktur yakni mendeskripsikan Flowchart, ERD, HIPO, Diagram konteks arah pengembangan sistem digunakan metode SDLC. Hasil yang diperoleh melalui ujicoba dengan petugas bahwa aplikasi ini sangat memudahkan pekerjaan mereka dapat mengurangi biaya dan waktu baik petugas maupun pemohon. Proses memasukkan dan menampilkan data menjadi lebih cepat dan efektif. Untuk fungsi aksi pada setiap form berhasil sesuai dengan fungsinya masing-masing. Maka, secara keseluruhan aplikasi berhasil dikembangkan sesuai dengan kebutuhan petugas.
\end{abstract}

Kata Kunci : Aplikasi Website, PHP, Terstruktur, Bootstrap4, SDLC, KPH Wilayah Kota Kupang

\section{PENDAhuluan}

Konsep welfare state atau negara kesejahteraan dianut oleh Negara Indonesia [1] diekspresikan dalam pembukaan UUD 1945 [2] bahwa sesungguhnya kemerdekaan itu ialah hak segala bangsa [3] dalam istilah umum merdeka yakni layak mendapatkan kesejahteraan. Sejahtera dalam keadaan baik, makmur, sehat damai dalam kebijakan sosial yang menunjuk kepada jangkauan pelayanan untuk memenuhi kebutuhan masyarakat. Usaha dan daya dimaksimalkan oleh pemerintah termasuk mengkaji reformasi birokrasi dalam rangka membangun sistem administrasi untuk melayani kepentingan rakyat [4]. Menurut [5] pelayanan publik bertujuan untuk meningkatkan kesejahteraan masyarakat, memberikan kepuasan dalam pelayanan, transparan yakni pelayanan bersifat terbuka, mudah dan dapat diakses oleh semua pihak yang membutuhkan. Pada prinsipnya implementasi pelayanan publik diemban atau menjadi tanggung jawab Instansi Pemerintah Pusat, Daerah, Lingkungan Badan Usaha Milik Negara/ Badan Usaha Milik Daerah.

Pembentukan Kesatuan Pengelolaan Hutan (KPH) merupakan amanat yang diatur dalam Peraturan Pemerintah
No. 6 Tahun 2007 dan Peraturan Pemerintah No. 3 Tahun 2008 tentang Tata Hutan dan Penyusunan Rencana Pengelolaan Hutan ditingkat daerah dengan fungsi pokok dan peruntukkannya dapat dikelolah secara efisien dan lestari. Keberadaan KPH memiliki peran yang strategis sebagai penyelenggara pengelolaan hutan di lapangan atau di tingkat tapak yang harus dapat memastikan bahwa pengelolaan hutan dilakukan secara lestari sesuai dengan fungsinya. Operasionalisasi KPH saat ini menjadi sebuah kebutuhan pemerintah dan pemerintah daerah sebagai pengurus sumber daya hutan sesuai mandat Undang-Undang dimana hutan dikuasai oleh negara dan harus dikelola secara lestari untuk sebesar-besarnya kemakmuran rakyat.

Sesuai dengan Surat Keputusan Menteri Kehutanan Nomor: SK. 591/Menhut-VII/2010 tanggal 19 Oktober 2010, telah ditetapkan Wilayah Kesatuan Pengelolaan Hutan Lindung (KPHL) dan Kesatuan Pengelolaan Hutan Produksi (KPHP) Provinsi NTT seluas \pm 1.247 .962 Ha terbagi menjadi menjadi 13 unit KPHL seluas \pm 689.609 Ha dan 9 unit KPHP seluas $\pm 558.353 \mathrm{Ha}$. Gubernur NTT dengan surat Nomor BU.522/34/Dishut/2017 tanggal 14 Juni 2017 mengusulkan perubahan penetapan Wilayah KPH Provinsi NTT menjadi 13 
unit KPHL dan 9 unit KPHP sehingga terhadap usulan Gubernur NTT tersebut Direktur Jenderal Planologi Kehutanan dan Tata Lingkungan dengan Surat Nomor S.1506/PKTL/REN/PLA.0/11/2017 tanggal 6 November 2017 menetapkan KPHL dan KPHP Provinsi NTT seluas \pm 1.132.925 hektar dibagi kedalam 22 unit KPH yang terdiri dari 13 unit KPHL seluas $\pm 593.809 \mathrm{Ha}$ dan 9 unit KPHP seluas $\pm 539.116 \mathrm{Ha}$ dan telah ditetapkan dengan Surat Keputusan Menteri Lingkungan Hidup dan Kehutanan Nomor : SK.664/MENLHK/SETJEN/PLA.0 /11/2017 tentang Penetapan Wilayah Kesatuan Pengelolaan Hutan Lindung dan Kesatuan Pengelolaan Hutan Produksi Provinsi Nusa Tenggara Timur. Dalam Lampiran Surat keputusan tersebut Kota Kupang ditetapkan sebagai KPHL Unit XVIII dengan fungsi kawasan hutan lindung seluas $\pm 1.440 \mathrm{Ha}$ dan Hutan Produksi seluas $\pm 59 \mathrm{Ha}$.

Untuk mengelolah hasil hutan di Kota Kupang masyarakat membutuhkan persetujuan dari KPH wilayah Kota Kupang dalam bentuk surat izin peredaran agar hasil hutan dapat di edarkan secara legal melalui urutan prosedur yang berlaku yaitu: 1). Masyarakat mengajukan permohonan ke $\mathrm{KPH}$ wilayah Kota Kupang untuk melakukan pengecekan lokasi tumbuh pohon (SPCL), 2). Diterbitkan Surat Tugas $\mathrm{KPH}$ wilayah Kota Kupang untuk melakukan pengecekan lokasi tempat tumbuh pohon, 3). Masyarakat mengajukan permohonan ke KPH wilayah Kota Kupang untuk melakukan pengecekan lokasi dan hasil penebangan pohon (SPCVP), 4). Diterbitkan Surat tugas KPH wilayah Kota Kupang untuk melakukan pengecekan lokasi dan hasil penebangan pohon, 5). Masyarakat membuat nota angkutan untuk dikirim ke KPH wilayah Kota Kupang, 6). Petugas KPH wilayah Kota Kupang menerbitkan berita acara dokumen nota angkutan sebagai bukti bahwa hasil hutan tersebut telah digunakan, Namun pelayanan izin di KPH wilayah Kota Kupang sering terhambat oleh karena jalur komunikasi antara petugas maupun pemohon terbatas oleh jarak, ketidaksiapan dokumen sehingga harus bolak balik, keterbatasan petugas apabila petugas yang menangani tidak berada ditempat sehingga proses pengecekan dokumen maupun lokasi sering terhambat mengakibatkan terlambat dan dapat menumpuk. Seiring dengan perkembangan teknologi saat ini, khususnya pada bidang website sebagai media informasi yang menawarkan berbagai kemudahan dalam menyajikan informasi [6]. Kecepatan dan kenyamanan merupakan dampak positif dengan adanya internet. Website lebih mudah diakses oleh masyarakat di berbagai daerah hanya dengan menggunakan internet.

Pelayanan publik perizinan peredaran hasil hutan di KPH wilayah Kota Kupang yang masih bersifat konvensional dan belum memanfaatkan secara aktif kemajuan teknologi informasi mengakibatkan ketidakefektifan penggunaan tenaga, biaya dan waktu, Oleh karena itu dibuatlah aplikasi website "Pelayanan Publik Perizinan Peredaran Hasil hutan p4H2 di KPH wilayah Kota Kupang” yang dapat membantu pelayanan izin di $\mathrm{KPH}$ wilayah Kota Kupang, guna memaksimalkan efektivitas kerja dari KPH wilayah Kota Kupang serta untuk memudahkan proses perizinan peredaran hasil hutan.

Orisinalitas riset ini terpaut dalam kajian kepustakaan menurut [7] dalam penelitian yang telah dilakukannya Dinas Kehutanan Kabupaten Kutai Timur belum menyelenggarakan pelayanan perizinan yang optimal sehingga diterapkan pola pelayanan terpadu dan mendapatkan apresiasi dikalangan pengusaha bergerak dibidang rehabilitasi hutan dan penggunaan lahan karena tidak melalui jalur birokrasi yang rumit. Lain halnya di Kabupaten Banyuwangi bahwa telah dibentuk Badan Pelayanan Perizinan Terpadu namun proses perizinan dan non perizinan belumlah efektif dan efisien [8], Perum Perhutani KPH Semarang telah mengembangkan sebuah aplikasi GIS dengan proses overlay untuk memetakan sumber daya hutan dan perencanaan reboisasi hutan [9] sedangkan Perum Perhutani KPH Saradan juga telah dikembangkan sebuah sistem informasi berbasis web untuk mengelola lahan kawasan hutan yang dapat memudahkan dan membantu dalam pencatataan dan laporan data pesanggem [10]. KPH Randublatung Kabupaten Blora mengembangkan aplikasi informasi Pemetaan hutan berdasarkan klasifikasi potensi hutan lindung untuk mengetahui letak lokasi hutan lindung, memberikan informasi wilayah hutan, serta letak lokasi hutan [11],[12] mengembangkan GIS bertujuan untuk mengetahui perubahan tutupan lahan dan penyebab terjadinya perubahan tersebut.

\section{Metodologi Penelitian}

Penelitian yang dikembangkan ini mengambil suatu pendekatan metodologi penelitian pengembangan perangkat lunak model konsevatif namun masih layak untuk digunakan yakni model SDLC menurut [13] metode ini tepat digunakan dalam merekayasa sistem dan perangkat lunak yakni mengubah sistem, model serta merancang sistem komputer dan konten informasi didalamnya sedangkan menurut [14] SDLC merupakan siklus hidup klasik yang menggunakan pendekatan pengembangan perangkat lunak dengan bersifat sistematis dan berurutan. Pada umumnya model ini masih sangat relevan untuk digunakan sehingga implementasi SDLC dalam penelitian ini dikembangkan agar mengarahkan bagaimana langkah demi langkah untuk penyelesaian pengembangan website p4H2 dimulai dari langkah 1). Perencanaan Sistem; 2). Analisis Sistem; 3). Desain Sistem; 4). Implementasi Sistem; 5). Perawatan Sistem. Untuk lebih jelasnya dapat dilihat pada gambar 1 berikut.

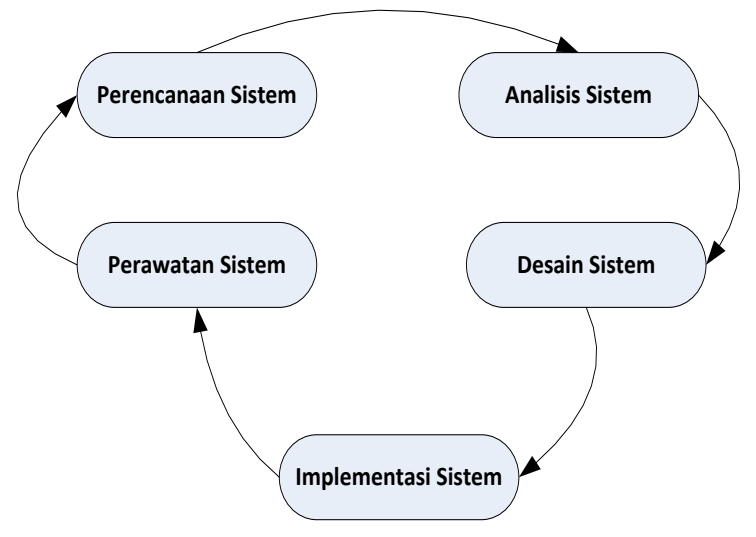


Gambar 1. Model SDLC Yang Digunakan

Pada Gambar 1 mendeskripsikan secara umum tahap demi tahap proses pengembangan suatu perangkat lunak yang akan dikembangkan. Untuk lebih jelasnya dapat diuraikan sebagai berikut.

\section{1) Perencanaan Sistem}

Sebagai awal dalam melaksanakan penelitian ini, kami melakukan tahap perencanaan yang dikelompokkan menjadi dua bagian yakni perencanaan pengumpulan data jangka pendek dan jangka menengah. Pada jangka pendek kami melakukan pengumpulan data yang meliputi observasi langsung, wawancara sehingga diperoleh informasi bahwa KPH Wilayah Kota Kupang membutuhkan sebuah aplikasi untuk menangani secara administrasi perizinan peredaran hasil hutan. Sedangkan untuk perencanaan jangka menengah apabila informasi yang dikumpulkan masih kurang, kami akan kembali untuk mengumpulkannya serta melakukan pengkajian secara empiris dengan mengumpulkan data-data karya ilmiah berupa jurnal, prosiding. Kemudian kami merencanakan/mengestimasi waktu yang akan diselesaikan untuk pengumpulan data, analisis, mendesain/koding dan perawatan sistem.

\section{2) Analisis Sistem}

Setelah informasi dikumpulkan dan dikelolah menjadi data, tahap selanjutnya menganalisis kebutuhan sistem. Pada dasarnya kebutuhan dalam pengembangan sistem secara umum terbagi atas tiga bagian yakni,

\section{a. Kebutuhan Pengguna}

Pengguna dalam penelitian ini dibagi menjadi dua yakni pengguna sebagai admin dan pengguna sebagai user (pemohon). Kebutuhan admin adalah bagaimana cara bisa berkomunikasi dengan sistem maka dibuatlah interface. Fasilitas admin 1). Memasukkan data user 2). Memasukkan berkas 3). Memasukkan nota dan 4). Memasukkan surah KPH. Sedangkat fasilitas user 1). Memasukkan data user 2). Memasukkan SPCL 3). Memasukkan SPCVP dan 4). Memasukkan nota.

\section{b. Kebutuhan Perangkat Lunak}

Fase analisis sistem untuk spesifikasi kebutuhan perangkat lunak dapat dilihat pada Tabel 1 berikut ini.

TABEL I

SPESIFIKASI KEBUTUHAN PERANGKAT LUNAK P4H2 DALAM TABEL

\begin{tabular}{lll}
\hline No & Nama PL & Kegunaan \\
\hline 1 & Sistem & Memberikan layanan konfigurasi \\
& Operasi Win & perangkat keras terhadap perangkat \\
& 10 Ultimate & $\begin{array}{l}\text { lunak yang akan diakses oleh } \\
\text { pengguna }\end{array}$ \\
& & Editor dari bahasa pemrograman
\end{tabular}

PHP untuk melakukan pengelolaan konten didalam aplikasi server

3 Cascading Untuk membuat halaman web yang Style Sheet dapat beradaptasi dengan berbagai macam ukuran layar

4 Hypertext Bahasa pemrograman yang Markup fleksibel yang mendukung Java, Language VB, C dan sebagainya. Digunakan (HTML) untuk mengembangkan aplikasi berbasis web

5 Hypertext Server side yang dirancang untuk Preprocessor aplikasi berbasis web

(PHP)

$6 \quad X A M P P \quad$ Sebagai server yang berdiri sendiri 7 Microsoft $\quad \begin{aligned} & \text { (localhost) } \\ & \text { Digunakan untuk mendesain }\end{aligned}$ Visio perancang sistem

8 Browser Digunakan untuk mengakses database baik secara lokal maupun non-lokal

9 Bootstrap 4 Digunakan untuk membuat aplikasi website agar dapat menyesuaikan dengan ukuran layar monitor apapun.

\section{c. Kebutuhan Perangkat Keras}

Terakhir dari fase analisis adalah menentukan spesifikasi kebutuhan perangkat keras yang akan digunakan dalam penelitian ini, untuk jelasnya dapat diuraikan pada Tabel 2 berikut.

TABEL II

SPESIFIKASI KEBUTUHAN PERANGKAT KERAS P4H2 DALAM TABEL

\begin{tabular}{|c|c|c|}
\hline No & Nama PL & Kegunaan \\
\hline 1 & $\begin{array}{l}\text { Processor } \\
\text { AMD A9-9425 } \\
\text { Radeon } R 5\end{array}$ & $\begin{array}{lrr}\text { Sebagai penggerak } & \text { untuk } \\
\text { menjalankan perintah } & \text { dan } \\
\text { mengatur alur kerja p4H2 } & \end{array}$ \\
\hline 2 & $\begin{array}{l}\text { Memori } 8 \mathrm{~Gb} \\
\text { Ram }\end{array}$ & $\begin{array}{l}\text { Media untuk menyimpan data } \\
\text { sistem }\end{array}$ \\
\hline 3 & $\begin{array}{l}\text { Printer Epson } \\
\text { L3110 }\end{array}$ & Media untuk mencetak laporan \\
\hline 4 & $\begin{array}{l}\text { Monitor } \\
\text { 14inch }\end{array}$ & $\begin{array}{l}\text { Perangkat keras ini sebagai media } \\
\text { untuk menampilkan interface } \\
\text { sistem agar pengguna dapat } \\
\text { berinteraksi. }\end{array}$ \\
\hline
\end{tabular}

3) Desain Sistem

Fase ketiga dalam proses pengembangan sistem model SDLC adalah mendesain sistem, dimana pada penelitian ini didesain beberapa fitur yakni :

\section{a. HIPO}

Pada Gambar 2 berikut ini mendeskripsikan hirarki sistem, pada level kedua terdapat Data Master, Data Transaksi dan View Data. Level ketiga input data user, 
input spcl, input spcvp, input nota, input surat $K P H$, input berkas, view berkas, view spcl, view spcvp, view nota, view surat $\mathrm{KPH}$.

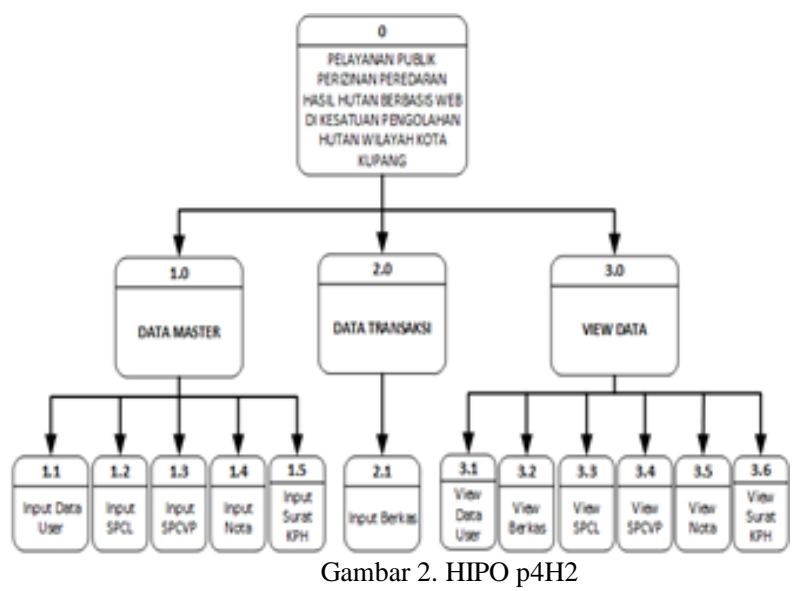

\section{b. Diagram Konteks}

Gambar 3 berikut ini mendeskripsikan alur kerja sistem dengan dua pengguna yakni admin dan user (Pemohon). Dari gambar tersebut dapat dijelaskan bahwa admin melakukan input data user, data berkas, input nota dan input surat KPH ke sistem serta admin dapat melihat data user, berkas, SPCL, SPCVP, nota, dan surat KPH. Sedangkan user dapat melakukan input data user, SPCL, SPCVP, nota ke sistem. Dapat melihat data user, berkas, SPCL, SPCVP, nota dan surat KPH.

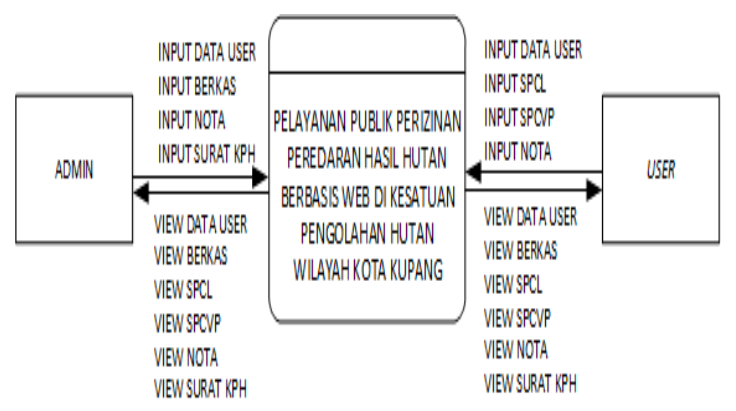

Gambar 3. Diagram Konteks p4H2

\section{c. ERD}

Perancangan sistem entitas relationship diagram (ERD) merupakan gambaran relasi pada sistem yang dalam penelitian ini dapat dideskripsikan sebagai berikut bahwa dapat dijelaskan bahwa satu spcl memiliki satu berkas yakni pada tabel dengan inisial nama yakni tbl_berkas dengan kd_berkas sebagai primary key dan pada tabel dengan inisial nama yakni tbl_spcl, kd_spcl sebagai primary key. Satu spcvp memiliki satu berkas yakni pada tabel dengan inisial nama tbl_berkas dengan kd_berkas sebagai primary key dan pada tabel dengan inisial nama tbl_spcvp, kd_spcvp sebagai primary key. Satu nota memiliki satu berkas yakni pada tabel dengan inisial nama tbl_berkas dengan kd_berkas sebagai primary key dan pada tabel dengan inisial nama tbl_nota, kd_nota sebagai primary key. Satu surat memiliki satu berkas yakni pada tabel dengan inisial nama tbl_berkas dengan kd_berkas sebagai primary key dan pada tabel dengan inisial nama tbl_surat, kd_surat sebagai primary key. Dari uraian tersebut dapat dilihat perancangan ERD pada Gambar 4 berikut.

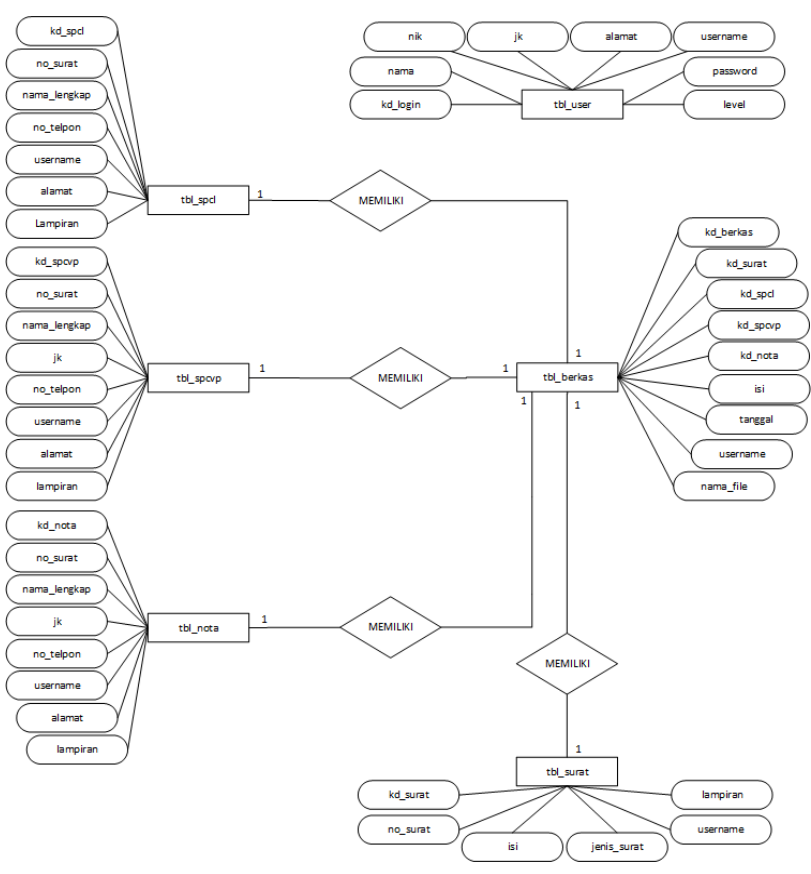

Gambar 4. ERD p4H2

d. Desain Antarmuka, diantaranya adalah :

\section{> Halaman Login}

Pada Gambar 5 berikut ini merupakan perancangan halaman user dengan tampilan untuk masuk ke sistem user harus memasukkan "Username" dan "Password" yang benar apabila salah maka sistem akan menampilkan proses login salah.

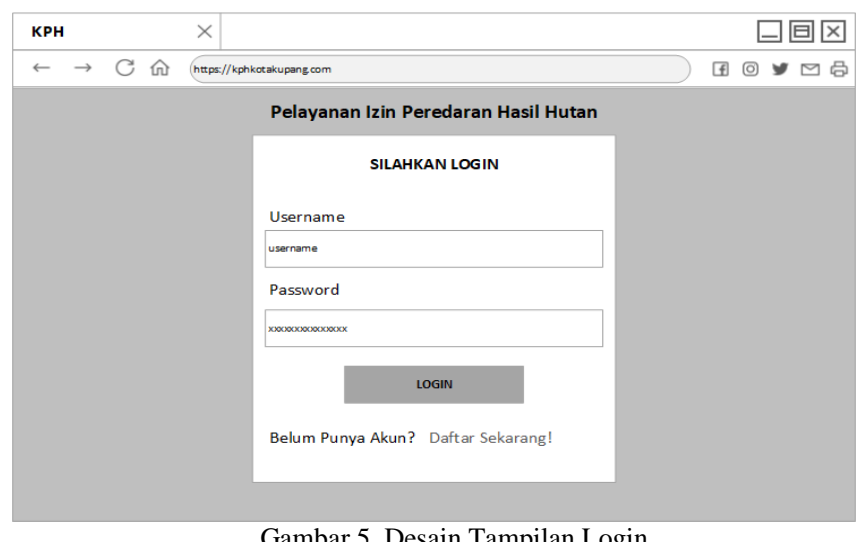

Gambar 5. Desain Tampilan Login 


\section{Halaman Dashboard}

Pada Gambar 6 mendeskripsikan perancangan tampilan menu utama atau dashboard yang dapat dilihat pada gambar berikut ini.

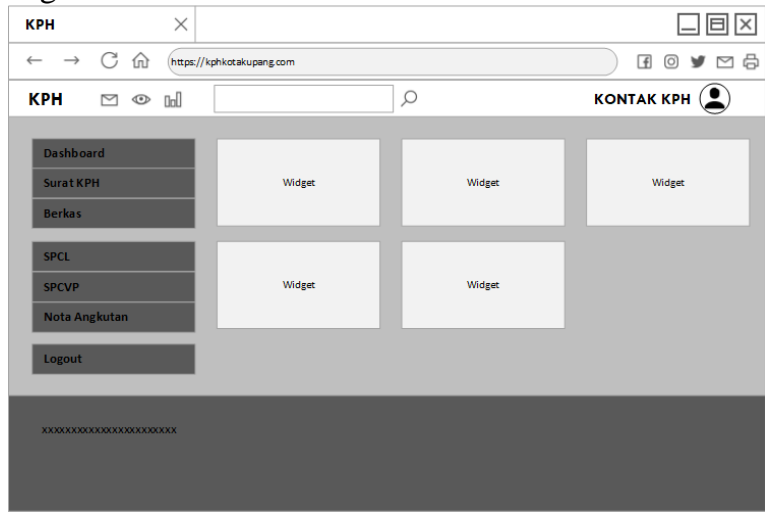

Gambar 6. Desain Halaman Dashboard

\section{- Halaman Surat KPH}

Pada Gambar 7 mendeskripsikan perancangan halaman surat $\mathrm{KPH}$, admin dapat mengelolah isi form dengan menambahkan, mengubah dan menghapus data surat KPH. Sedangkan user hanya dapat melihat data surat tidak bisa mengelolah isinya, dapat dilihat pada gambar berikut ini.

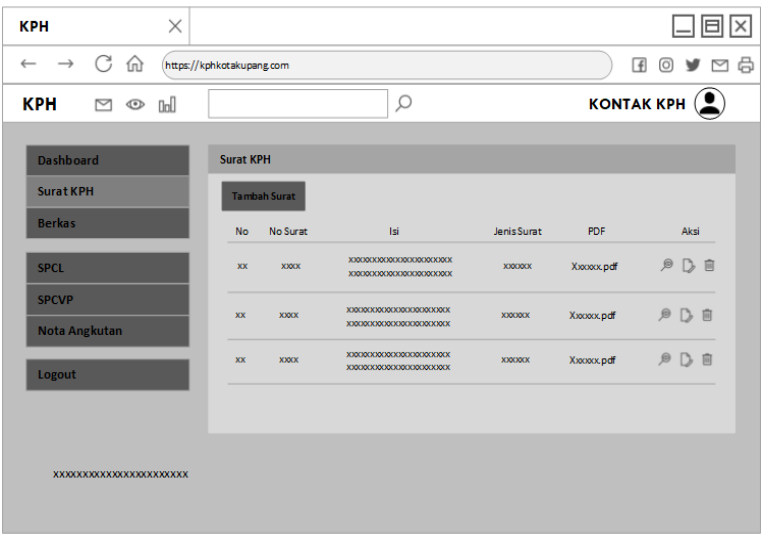

Gambar 7. Desain Halaman Surat KPH

\section{Halaman Berkas}

Pada Gambar 8 menunjukkan perancangan halaman berkas, dimana admin dapat menambahkan, mengubah dan menghapus data surat. Sedangkan user hanya dapat melihat isi form berkas. Dapat dilihat pada gambar berikut.

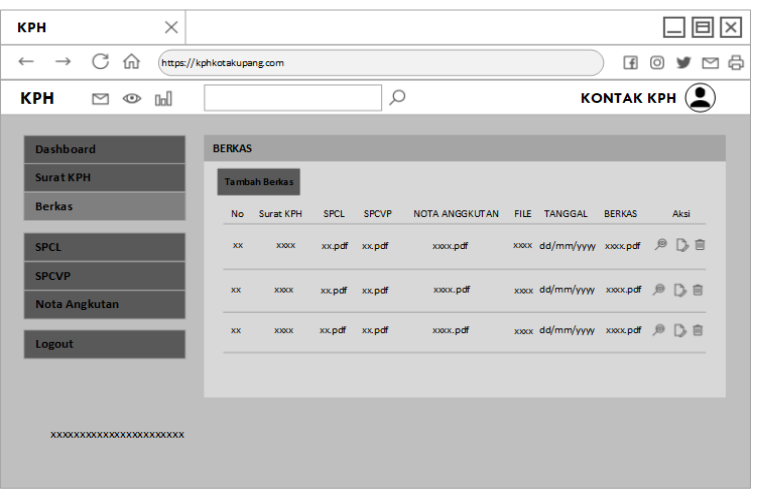

Gambar 8. Desain Halaman Berkas

\section{Halaman SPCL}

Pada Gambar 9 menunjukkan perancangan halaman SPCL, dimana user dapat menambahkan, mengubah dan menghapus data SPCL. Sedangkan admin hanya dapat melihat isi form SPCL. Dapat dilihat pada gambar berikut.

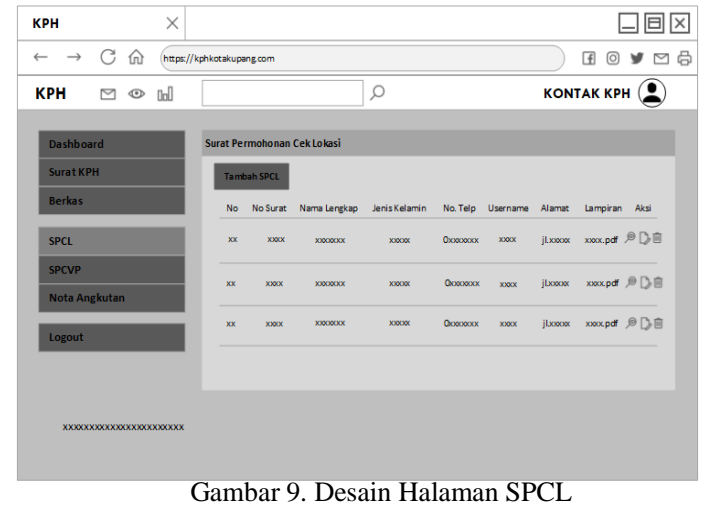

\section{Halaman SPCVP}

Pada Gambar 10 mendeskripsikan perancangan halaman SPCVP, dimana user dapat menambahkan, mengubah dan menghapus data SPCVP. Sedangkan admin hanya dapat melihat isi form SPCVP. Dapat dilihat pada gambar berikut.

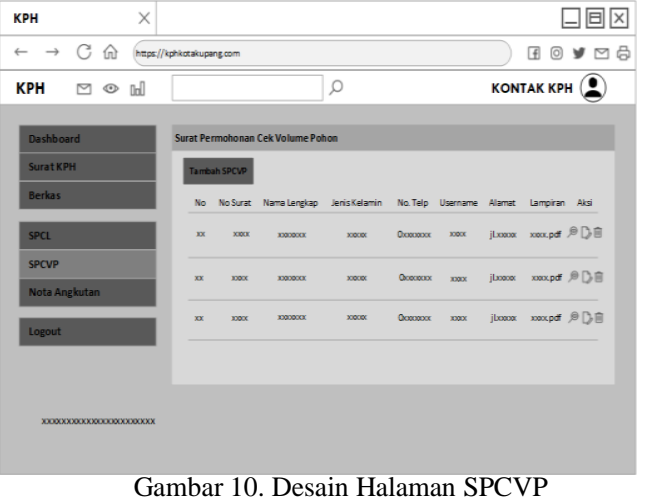

\section{Halaman Nota Angkutan}

Pada Gambar 11 mendeskripsikan perancangan halaman nota angkutan, dimana user maupun admin dapat menambahkan, mengubah dan menghapus data nota angkutan. Dapat dilihat pada gambar berikut.

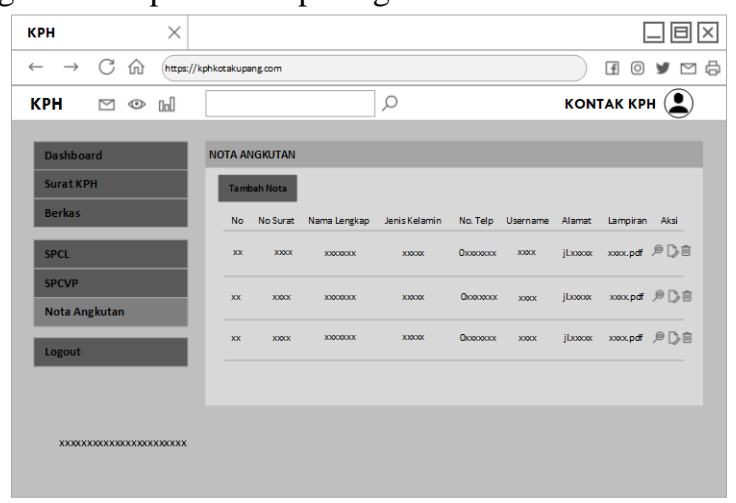




\section{4) Implementasi Sistem}

Gambar 11. Desain Halaman Nota Angkutan

Langkah keempat model SDCL adalah melakukan penerapan terhadap perancangan sistem yang telah dibuat terlebih dahulu (lihat bagian Desain Sistem dan Desain Antarmuka). Pada penelitian ini implementasi sistem secara detail dapat dilihat pada bagian III Hasil.

\section{5) Perawatan Sistem}

Langkah terakhir model SDLC adalah perawatan sistem, langkah ini diimplementasikan pada pengembangan sistem p4H2 apabila sistem mengalami error dalam bentuk apapun.

\section{HASIL DAN PEMBAHASAN}

Pada fase keempat metode SDLC pada penelitian ini, untuk mengakses aplikasi sistem p4H2 baik admin dan user harus terlebih dahulu menyiapkan browser. Kemudian halaman login akan ditampilkan seperti pada Gambar 12. Sedangkan untuk user baru terdapat halaman daftar seperti pada Gambar 13 dengan harus mengisi terlebih dahulu informasi pribadi yakni : Nama lengkap, NIK, Jenis Kelamin, Alamat kemudian memilih Daftar.

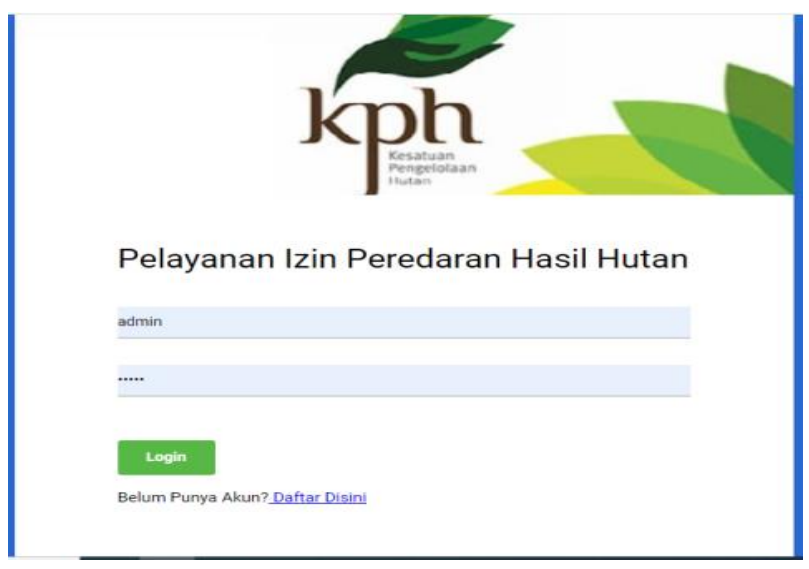

Gambar 12. Implementasi Tampilan Login

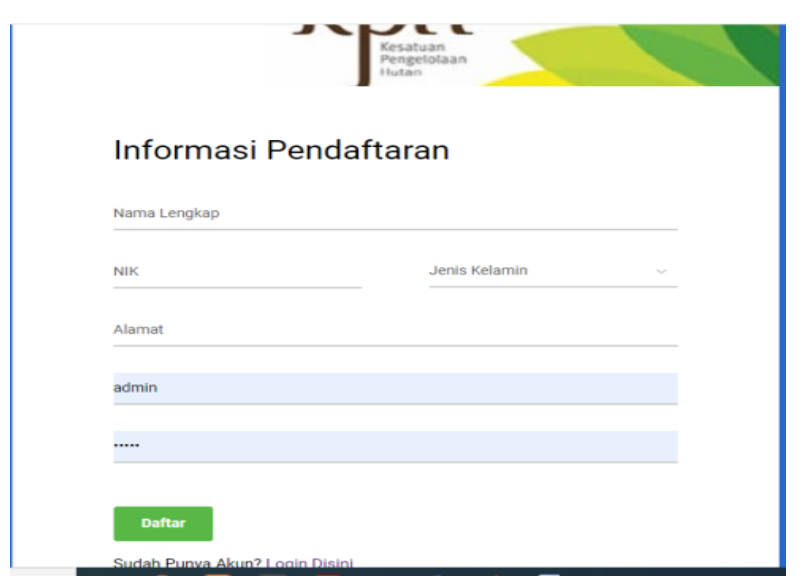

Gambar 13. Implementasi Tampilan Daftar User

Setelah proses login berhasil, sistem akan menampilkan tampilan dashboard merupakan pusat kontrol panel dengan fungsi mengatur semua alur kerja dalam situs. Dashboard ditampilkan pada halaman awal situs yang terkait dengan database yang memungkinkan admin maupun user dapat mengakses halaman lainnya sesuai dengan hak akses masingmasing. Dapat ditunjukkan pada Gambar 14 berikut ini.

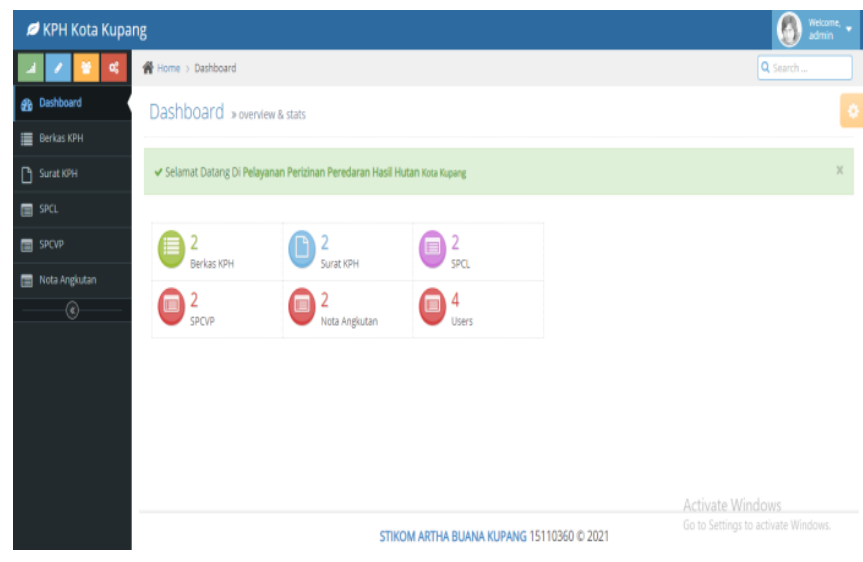

Gambar 14. Implementasi Tampilan Dashboard

Pada halaman dashboard tersedia fasilitas informasi berkas KPH, surat KPH, SPCL, SPCVP, dan nota angkutan. Untuk tampilan pada form halaman surat KPH berisi informasi jumlah dan jenis surat berita acara dengan hak akses dapat mengunggah surat, mencari, mengubah, melihat dan menghapus yang dapat dikerjakan oleh admin. Dapat dilihat pada Gambar 15 berikut.

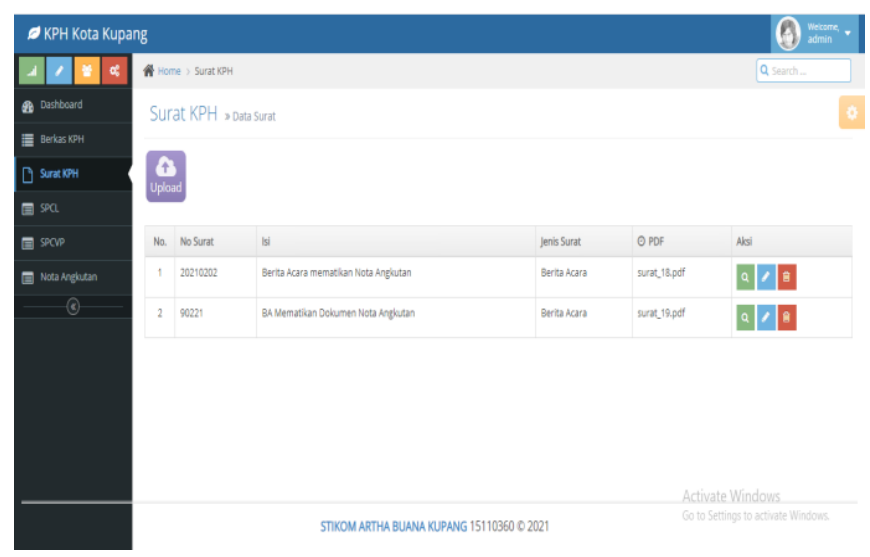

Gambar 15. Implementasi Tampilan Surat KPH

Pada Gambar 16 berikut mendeskripsikan tampilan secara eskplisit bahwa user memiliki hak akses untuk mengelolah informasi berupa mengunggah, mencari, 
mengubah, melihat dan menghapus informasi. Pada tampilan tersebut pula diinformasikan No Surat, Nama Lengkap, Jenis Kelamin, No. Telp, Username, Alamat, dan Lampiran sebagai data SPCL demikian juga untuk Gambar 17 berikut ini menampilkan informasi SPCVP dan Gambar 18 menampilkan informasi nota angkutan, serupa dengan Gambar 16.

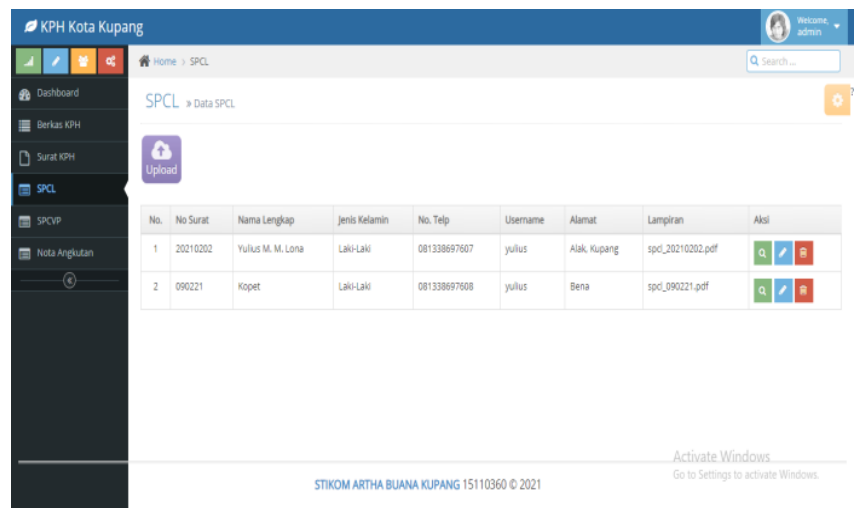

Gambar 16. Implementasi Tampilan SPCL
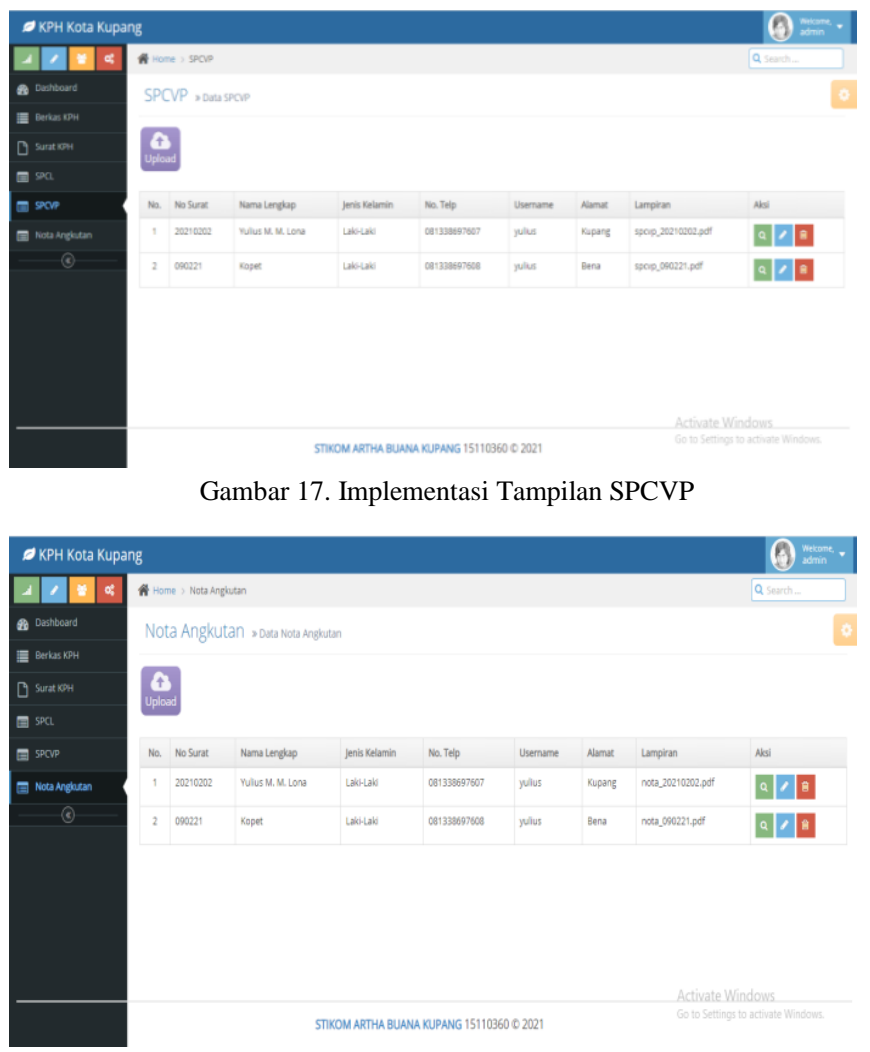

Gambar 18. Implementasi Tampilan Nota Angkutan

Adapun hasil dari penelitian ini berupa pengembangan aplikasi berbasis website untuk memudahkan petugas $\mathrm{KPH}$ Wilayah Kota Kupang dalam menerbitkan surat peredaran hasil hutan. Dimana sebelumnya pemohon harus mendatangi kantor KPH dengan membawa serta semua kelengkapan administrasi setelah itu melakukan pengajuan permohonan untuk dilakukan pengecekan lokasi tumbuh (SPCL), kemudian petugas melaporkan kondisi/keadaan, apabila semua sudah memenuhi prosedural maka Surat Tugas dikeluarkan untuk dilakukan pengecekan lokasi tempat tumbuh pohon, kemudian pemohon mengajukan kembali surat permohonan untuk pengecekan lokasi dan hasil penebangan pohon (SPCVP), lalu diterbitkanlah Surat Tugas untuk melakukan pengecekan lokasi dan hasil penebangan pohon dan pemohon membuat nota angkutan untuk diserahkan kepada petugas KPH. Petugas KPH menerbitkan berita acara dokumen nota angkutan sebagai bukti bahwa hasil hutan telah digunakan. Dari alur/proses yang konvensional tersebut, maka dibuatkanlah sebuah sistem berbasis website agar pemohon/user dapat melengkapi berkas permohonan tanpa harus mendatangi kantor $\mathrm{KPH}$, bisa diakses langsung dari tempat tinggal masing-masing. Demikian pula petugas apabila berhalangan/tidak hadir dikantor bisa mengecek apabila terdapat permohonan untuk peredaran hasil hutan. Pada Gambar 19 berikut ini merupakan tampilan halaman berkas, dimana petugas/user akan mengecek kelengkapan berkas dari pemohon terdiri atas Surat KPH, SPCL, SPCVP, Nota Angkutan, File berisi keterangan Pemohon, Tanggal permohonan/waktu menggungah dokumen, dan Berkas untuk menampilkan dokumen lampiran. Sedangkan hak akses petugas adalah dapat melakukan pencarian, melihat, mengubah dan menghapus dokumen.

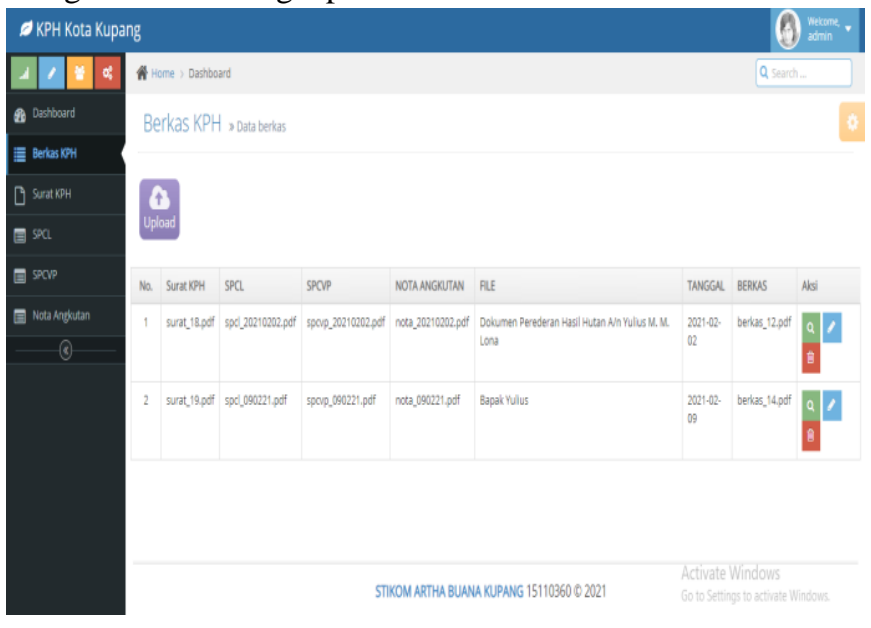

Gambar 19. Implementasi Tampilan Halaman Berkas

\section{KESIMPULAN}

Melalui tahap demi tahap penerapan model pengembangan sistem SDLC hasil yang diperoleh sangat baik adanya karena seluruh proses/alur pada sistem mengadopsi kondisi yang terjadi di KPH Wilayah Kota Kupang yang diimplementasikan kedalam bentuk form form. Setelah diadakan ujicoba dengan petugas, bahwa aplikasi ini sangat memudahkan pekerjaan mereka dapat mengurangi biaya dan waktu baik petugas maupun pemohon. Proses untuk memasukkan dan menampilkan data menjadi lebih cepat dan 
efektif. Untuk fungsi aksi pada setiap form berhasil dibuat sesuai dengan fungsinya masing-masing. Maka, secara keselurahan pengembangan aplikasi p4H2 ini berhasil dikembangkan dengan baik sesuai dengan kebutuhan petugas.

\section{UCAPAN TERIMA KASIH}

Terima kasih disampaikan kepada KPH Wilayah Kota Kupang yang telah mengizinkan kami untuk melakukan penelitian sehingga aplikasi ini dapat dikembangkan. Terima kasih juga kami sampaikan kepada Pimpinan STIKOM Artha Buana Kupang yang mengizinkan kami untuk melakukan penelitian

\section{REFERENSI}

[1] Z. A. M. Di et al., "Indonesia merupakan negara," vol. 5, no. 8, pp. 1-11, 2016.

[2] N. R. Yunus, "Aktualisasi Welfare State Terhadap Kehidupan Bernegara Dalam Dimensi," Mizan J. Ilmu Syariah., vol. 3, no. 2, pp. 253-276, 2015.

[3] O. Sukmana, "Konsep dan Desain Negara Kesejahteraan ( Welfare State ) Pendahuluan Dewasa ini , wacana mengenai negara kesejahteraan ( welfare state ) menjadi didefinisikan sebagai suatu negara dimana pemerintahan negara dianggap bertanggung jawab dalam menjamin standa," Sospol, vol. 2, no. 1, pp. 103-122, 2016.

[4] Yusriadi and Misnawati, "Reformasi Birokrasi dalam Pelayanan Publik (Studi Pelayanan Terpadu Satu Pintu)," J. Ilm. Ilmu Adm. Publik, vol. 7, pp. 99-108, 2017.

[5] S. Suhartoyo, "Implementasi Fungsi Pelayanan Publik dalam Pelayanan Terpadu Satu Pintu (PTSP)," Adm. Law Gov. J., vol. 2, no. 1, pp. 143-154, 2019, doi: 10.14710/alj.v2i1.143-154.

[6] Y. Trimarsiah and M. Arafat, "ANALISIS DAN PERANCANGAN WEBSITE SEBAGAI SARANA," J. Ilm. MATRIK, vol. 19, no. 1, pp. 1-10, 2017.

[7] D. Wahyudi, "Pelayanan Perizinan Bidang KehutananPada Kantor Dinas Kehutanan DiKabupaten Kutai Timur,” Paradigma, vol. 3, no. 3, pp. 2252-4266, 2014.

[8] F. Hidayat, B. S. Sunarko, P. Magister, and I. Administrasi, "IMPLEMENTASI PELAYANAN TERPADU SATU PINTU (PTSP): PENDELEGASIAN KEWENANGAN SETENGAH HATI (Studi terhadap Penyelenggaraan PTSP di Badan Pelayanan Perizinan Terpadu Kabupaten Banyuwangi)," vol. 18, no. 1, pp. 144-163, 2018.

[9] S. HENDRI, "Sistem Informasi Geografis (SIG) Hasil Sumber Daya Hutan Dan Reboisasi Di Wilayah Perum Perhutani KPH Semarang," UDINUS Repos., 2014.

[10] A. Pahlevi, "Sistem Informasi Pengelolaan Lahan Kawasan Hutan Berbasis Web," DoubleClick J. Comput. Inf. Technol., vol. 2, no. 1, p. 16, 2018, doi: 10.25273/doubleclick.v2i1.3215.

[11] T. D. Pamuji, "Sistem Informasi Geografi ( Sig ) Pemetaan Hutan Menurut Klasifikasi Sebagai Potensi Hutan Lindung Di Kabupaten Blora," J. Chem. Inf. Model., vol. 53, no. 9, pp. 1689-1699, 2013.

[12] H. Hutagaol, "Analisis Tutupan Lahan Di Wilayah Kerja Kesatuan Pengelolaan Hutan (KPH) Sintang Utara Menggunakan Sistem Informasi Geografis Ria," PIPER, vol. 15, no. 29, pp. 224-233, 2019.

[13] S. B. Hartono, "Pengembangan Sistem Informasi Arus Kas Dengan Metode Sdlc (System Development Life Cycle) Pada Madin Al-Junnah," ISOQUANT J. Ekon. Manaj. dan Akunt., vol. 4, no. 1, p. 1, 2020, doi: 10.24269/iso.v4i1.337.

[14] I. W. Eka, P. Putra, I. G. M. Darmawiguna, and I. M. Gede, "Pengembangan Aplikasi Android: Classroom Schedule and Activity Information Menggunakan Qr Code," vol. 5, 2016. 